Online: http://journal.uny.ac.id/index.php/jppfa

\title{
A STUDY OF THE PROFESSIONAL COMMUNITY OF TEACHERS IN EQUITY OF TEACHING QUALITY
}

\author{
Mousafi Juliasandi ${ }^{1}{ }^{*}$, Arif Rohman ${ }^{1}$ \\ ${ }^{1}$ Universitas Negeri Yogyakarta \\ ${ }^{1} \mathrm{Jl}$. Colombo No. 1, Depok, Sleman 55281, Yogyakarta, Indonesia \\ * Corresponding Author. Email: mousafi.juliasandi2016@student.uny.ac.id
}

\begin{abstract}
The high level of educational participation has not guaranteed the quality of education in a country. Especially developing countries, the issue of educational participation can be overcome with the maximum, but the problem that is still the agenda in various countries is about the equalization of the quality of education. This article is an article compiled based on literature review of the issues. One of the key factors causing inequality in the quality of education is the irregularity of the quality of educators which ultimately affects the inequality of teaching quality. The literature study conducted finding the teacher community is an effective solution to solve the problem. The professional community is an association of teachers to interact with each other and communicate in an integrated learning and teaching improvement. The professional community of teachers is considered to be able to overcome the quality of educators who are located in remote areas. The activities of this professional community of teachers can also be maximized by the use of various media such as internet network. Addressing the gap in teaching quality between remote and airspace will ultimately be able to address the inequalities of appropriate educational quality.

Keyword:equalization of teaching quality; professional community of teachers
\end{abstract}




\section{INTRODUCTION}

The level of educational participation from year to year continues to increase, especially at the level of primary education to secondary education. The success of increasing educational participation in developing countries can be seen by the high number of educational participation in several levels of education, especially basic education. However, the high rate of educational participation has not been matched by improvements in the quality of education in developing countries such as India, Bangladesh, Vietnam, Indonesia, etc. This increase in educational participation is not matched by improving the quality of education in developing countries. Various surveys conducted by the OECD (2016, pp. 469-475) in OECD countries and partner countries includeing developing countries, with various indicators putting the growth rate constantly below average.

One of the factors of poor quality of education in developing countries is the inequality of the quality of education in these countries. The quality of teachers must be continuously improved. Professional teachers carry out their obligations based on professionalism that will continue to improve quality through education and training. The success of an effective school depends very much on the quality and credibility of the teaching staff in it (Nurhayati, 2017). On a larger scale, the quality of education of a country depends very much on the quality of its educators. UNESCO at the launch of Global Education Monitoring (GEM) Report (2016), highlighting the educational quality gap in developing countries. The quality of education gained by children in the interior of Kalimantan and Papua is very different from that obtained by children in urban areas such as Jakarta and Yogyakarta. Various constitutions that regulate the right of every citizen to get an education do not apply to those remote areas.

Unevenness in the quality of education in developing countries is caused by various factors. Geographical Developing country which is an archipelagic country, and also limited access to reach areas is one factor. Various grants from education funds amounting to $20 \%$ of the state budget as if not touching areas with predicate Front, Outermost, and Disadvantaged (Al-Samarrai \& Cerdan-Infantes,
2013, p. 115). The process of disbursing funds that are not appropriate and irrelevant to the educational needs of developing countries is also one of the factors causing it. In addition, there are still areas with very low educational aspirations such as in rural Sulawesi, Kalimantan, Irian, and Papua. This is due to the culture and mindset of the people who think that education is not an important thing to strive for, of course it is also for the quality of developing country education to awaken its citizens that education is a long-term investment in life and personality.

One of the key factors of this gap is the difference in teacher competence in each developing country region. The quality of education of a country depends largely on the quality of its educators. The various disparities that exist between urban and remote areas in developing countries, print teacher competencies that also have gaps. The quality of teachers in the interior is very different from the quality of teachers in urban areas, ranging from educational background, experience, to their teaching motivation. Developing country governments have made various efforts to resolve this inequality of teaching with the program that places teachers who are considered competent in their fields to teach in disvantadge areas. But the essence of this program becomes changed when we see it only as a requirement of formality in achieving the level of career establishment. Many teachers once they are placed in remote areas and return to their urban areas with a level of professionalism that is considered qualified based on the experience they have been through, no longer willing to teach in remote areas and choose to teach in urban areas. As a result, the gap in teaching quality that lies between remote and urban areas finds no solution.

The professional community is one of the effective strategies in teacher competence development (Bobby, Starnes, Saderholm, \& Webb, 2010; Cesareni, Martini, \& Mancini, 2011; Chou, 2011). The professional community is an association of educators who conduct various activities together to develop the quality of their teaching. In addition to individual positions, teachers also play a role as a member of a school system, as do their students or learners. Teachers vary in age, background, experience, and also how they respond to the things they face in life and in teaching (Boyle- 
Balse, 2005). Thus, the competence of each teacher is certainly different from the experiences they experience in solving problems in their classroom. Teachers' communities can be a place for them to share experiences, innovations, content, solve problems and build attachments among teachers as a means of developing their competencies and professionalism. Optimizing the professional community of primary school teachers is a solution of inequality in the quality of teaching in developing countries.

The teacher has several competencies that must be possessed in the professional aspect (Farisi, 2011). The first competency is pedagogical competence in which a teacher is required to have ability in the ability to manage their learning and teaching. The second competence is the personality competence in which a teacher is a person with a good personality, authoritative, wise, and able to be an example for their learners. Professional competence is the next competence, where a teacher is required to master the depth of material of what is delivered. The next competence is social competence where a teacher is also a member in the community system, the teacher must be able to have the ability to communicate with his or her social environment, both with the community, fellow teachers, students, and parents and guardians of the students. These competencies must be owned and developed by educators to become effective and qualified teachers to improve the quality of teaching and ultimately improve the quality of education.

Demirkasimoğlu (2010) stated the meaning of teacher professionalism as:

"Professionalism is interpreted in terms of what extent the teachers outcome the difficulties and what extent they are able to use their skills and experiences related to their profession. On the most basic level, "professional teacher refers to the status of a person who is paid to teach'; on a higher level, it can refer to teachers who represent the best in the profession and set the highest standards."

The opinion suggests that teacher professionalism can be seen from the extent to which the teacher is able to face difficulties and solve them. Not only that, the teacher must also be able to use skills and experiences related to professional interests. High-level professional teachers, teachers do not refer to the status of people who are paid to teach but are able to set the highest standards.

Education is always transformed to keep pace with the changing culture of human civilization. Science is not static, but continues to grow rapidly as a result of the rapid development of communication. Professional teachers need to be kept up to date on these developments. Discussion activities become important for teachers to exchange information about new sciences, materials, methods, or new ways of solving problems. The difference in experience facing different classes is an interesting discussion material for discussion between teachers. Broad thinking needs to be developed. Professional teachers must have a wealth of perspectives and paradigms in addressing various things that might occur when teaching in class. Discussion among fellow teachers plays an important role in this matter, to support the exchange of knowledge and experience between the two.

Do not stop at discussions, cooperation between teachers needs to be built. The teacher has responsibility for the class, but that does not mean that it is only holding the teacher isolated in his class. It is also necessary for teachers to collaborate on the progress of both and students. Productive collaboration between teachers needs to be created. The joint commitment to improve the quality of learning has become a strong reason for establishing productive collaboration. But differences in teacher characteristics individually are sometimes a barrier to a good climate of communication and collaboration.

In addition to individual positions, teachers also play a role as a member of a school system, as do their students or learners. Teachers vary in age, background, experience, and also how they respond to the things they face in life and in teaching (Lieberman \& Miller, 2008). Thus, the competence of each teacher is certainly different from the experiences they experience in solving problems in their classroom. It is in these differences that the role of a professional community is crucial.

A professional community is a community where educators or teachers come together to exchange teaching experiences (Day, Sammons, Stobart, Kington, \& Gu, 2007). The communities we know exist in Indonesia and 
are governed by law are Kelompok Kerja Guru (KKG). The KKG is an association of teachers in one school cluster.

Handy (1976) shows that a community needs time and effort to develop into a team that will work together effectively. According to Handy, there are four stages in how community will become an effective team:

\section{The Community Forms}

Most communities are formed of one person who is the chairman because of a problem that must be solved, changes that must occur, and decisions that must be made. At this stage most community members feel anxious and too dependent on the chairman. This stage is also likened to water testing, because no one is sure about what attitude can be received by other members of the community who will find their duties as a whole, how they will deal with it and what results are expected.

\section{The Community Storms}

This second stage is common for most communities. This happens when members do not understand and there are conflicts between sub-groups and frequent revolts against the chairman. It is difficult to give reasons why this happened. There will be resistance to control and community members as if affirming their individuality compared to having to join the community. In addition, there is also resistance to work and most members also feel that the assignment is not important to them.

\section{The Community Norms}

During this stage, the community began working together like a team and more collaboration emerged. This happens because resistance to the chairman or the task has been completed and the conflict has also been resolved. Besides that there is also a feeling of mutual support. At this stage there is a lot of work being done because of open exchanges of views and greater cooperation in order to reach reasonable and valuable decisions.

\section{The Community Performs}

At this stage the community is a team that works to solve problems and achieve results. They want to get the job done. At this stage there are only a few interpersonal prob- lems and team members know each other well and have developed work relationships that make them come forward. Solutions and results of results arise and there are constructive efforts to meet the regulated deadlines.

Handy added that it would be better if all four stages occur in the shortest possible time. This is because the main goal of a team is to create a solution that results from collaborative collaboration rather than individually.

Mc Laughlin \& Talbert (2006) distinguishes between two types of teacher communities. The two types are "traditional communities" and then with what they call the "teacher learning community". Teachers in traditional communities share well-defined views of the content they teach and what students should learn, but they show little inclination to question the view even in the face of student difficulties or failures. In contrast, the teacher learning community is united by their commitment to student learning and the tendency to inquire deeply about the problems of teaching and learning. As used by McLaughlin and Talbert, the term "teacher learning community" refers to the teacher's shared efforts to generate new knowledge from practice and support each other's professional growth. So it can be concluded that a community of teachers will be strong if they have a mission in their community amid various competence differences they have. This purpose or mission equation is of course to improve the quality of their teaching and learning in order to improve the quality of education.

\section{CRITICAL REVIEW AND DISCUSSION}

Maybe we can assume that the work that the teacher is doing together may be ambitious or superficial; the relationship they build may be harmonious or ridden by individual needs; the existence of a close group might unite or even create a school split. Apart from all the assumptions that exist, the facts show that the teacher professional community has a significant positive impact on the teacher, students, and school culture. A teacher must have knowledge in a context that is constantly changing following the evolving needs and problems that exist today (Stoll, Bolam, McMahon, Wallace, \& Thomas, 2006). So in this case the development of a sustainable 
teacher's competence is an inseparable part of their status as an educator.

\section{Teachers' Professional Community as Containers for Increasing Competence}

A teacher should be not just someone who has pedagogical abilities and knowledge, but also as a creator, a spreader, as well as a pioneer (Wood, 2007). The teacher community provides an opportunity for teachers to develop their competence not only as passive recipients of knowledge but also as the creators, pioneers and disseminators of such knowledge.

In a teacher community, teachers can reveal learning problems that have not yet solved them (Warren Little, 2003). With various experiences and wealth of knowledge of teachers together, discuss effective solutions to solve the problem. This activity will of course improve the quality of teaching both individually and as a whole because other teachers also gain the experience. Indonesia with a very high student complexity certainly has various problems that vary in the various conditions of the learning environment. Not every teacher can gain experience with the problems that other teachers have, so in the teacher community can provide anticipation when teachers get the same problem with the issues that have been discussed.

The professional community of teachers is also a medium for teachers to be able to develop learning methods for their students (Cheng \& Tsui, 1999). Every teacher certainly has a tendency to use using a method in classroom learning. This tendency of course makes a teacher has more knowledge and experience on the learning method. Different trends in each teacher can be a capital for teachers to combine, collaborate, and develop their classroom learning methods.

The teacher professional community creates an attachment between teachers as colleagues. This attachment will of course affect the development of competence. With the attachment of teachers will encourage each other to be able to continue to develop the ability and continue to innovate. This attachment also eliminates the distance between junior and senior teachers, or permanent teachers and honorary teachers who often cause gaps among teachers and become one factor ineffectiveness of teacher performance in learning (Andrews \&
Lewis, 2002). Levine also revealed that schools that maintain the collaborative 'professional community of teachers' over time can create resources that help teachers to change aspects of their work (Levine, 2011). These resources include: the teacher's desire to innovate; broad common goals; trust; continuity with the past; and also high appreciation for teachers.

An effective professional community will show the high intensity of communication among teachers, which of course the communication is focused specifically on teaching and learning. Teachers in the professional community will communicate more often about the progress of their students, develop curriculum as well as assessment instruments together and also help other teachers to observe their learning in order to gain a representative reflection of their learning (Talbert \& Mclaughlin, 2002). Teachers with lots of experience can guide new teachers in their learning (Scott, 2005). Teachers can compare students' work or writing results. Teachers with different disciplinary sciences can determine each other's authentic relationships between subjects to develop thematic learning in their classroom.

\section{Equal Quality of Teaching with the Professional Community of Teachers}

Based on a literature review of the professional community of teachers, it is clear that the teacher community is one of the most effective strategies for developing and improving teacher competence. However, how can a professional community of teachers solve the problem of inequality of teaching in developing country? Optimizing professional community activities supported by schools as well as governments, is the answer to that question.

The first phase of this optimization should be done in the teacher community in urban areas with adequate resources and competence support. The ineffectiveness of teacher community activities is due to the difficulty of teachers to set aside time to meet each other, this is due to various factors such as space, teaching hours demands, and schools that do not support it (Hur \& Brush, 2009). One strategy to optimize this activity in urban areas is through a professional community of teachers online using the internet network (DuncanHowell, 2010). 
The Internet today provides almost limitless freedom for its users, eliminating distance, time and various limitations. It can be utilized to create professional community teacher activities online so that teachers are more flexible in communication whenever and wherever. In many countries around the world, this has been well implemented and has a very positive impact on improving the quality of education (UE, Outlook, \& UE, 2014). For example in a French country that has an online community platform run by the French Ministry of Education which includes 2500 work innovations from teachers participating in the platform. It is also in Sweden that has an educational website with three general objectives of information, online resources and communication room for more than 100 teachers who participate in it.

One of the most easy to use and representative media for the condition of teachers in Indonesia who in fact still lack experience in terms of operation of technology is the media Blog. Blog which stands for Web Log is an easy-to-use website that contains image text, video or links to other websites (Byrd, 2011). Bloggers who post and update information on Blogs do not need to be familiar with HTML (hypertext markup languange), and Blogs are easy to use just as easily as using a word processing program. Information is easy to upload by sending from computer to Internet and allowing that information to be shared with a wider audience (teachers in the community) (Yang, 2009). Blogs do not cost anything other than less time, will, and also internet connection. The author believes that blogs are the perfect medium for educators to communicate, share, publicize, and manage information. Blogs provide a place where teachers can communicate with each other and participate in socially constructed communities through collaborative electronic discourse.

Technically, blogs can be organized according to the needs of teachers, teachers can set blogs accessible using passwords or accessible freely by a wide audience. Blogs can be used to publish something like an innovative learning method, student learning outcomes, or the work of their students (Tang \& Lam, 2014; Wang, 2011). Teachers can interact through comment and post fields. Several studies have proved the effectiveness of Blogs in building an alternative teacher community that is also effective as the development of user competence (Hou, Chang, \& Sung, 2009; Tang \& Lam, 2014; Wang, 2011; Yang, 2009).

After optimizing the professional community of teachers is optimized, the next is to optimize the teacher community in remote areas. The lack of access to remote areas makes the teacher community in the area unoptimal, and it is not possible for teachers with competent competencies who live mostly in urban areas to come to remote areas. One attempt to optimize the professional community of teachers in remote areas is to use media, such as videos or books.

With the support of the government, it is likely to be implemented in Indonesia. The community of teachers in which there are various experiences, criticizing the concept and also innovating, can be immortalized in a video or book media. After the results of this community activity are immortalized in the video or book media, then the book and video are reproduced and sent to teachers in remote areas. through video media or books that are the result of the activities of the urban community of teachers, teachers in remote areas will also gain experience and knowledge that teachers also get in the professional community of teachers in urban areas. Rural teachers can also address their issues in the form of recording that can later be discussed in the community of teachers in urban communities.

The role of government in supporting the implementation of this activity is very influential. As in the case of reproducing videos or books as medaia in the professional community, distributing the videos or books to teachers in remote areas through their respective local governments, to providing video recorders and video players for remote teachers. Sharing and accepting experiences through video or book media can add teachers' experience and knowledge to improve and improve their teaching quality (Van Es, 2012). This should be done on an ongoing basis, so that the gaps in teacher teaching competencies in remote and urban areas can be resolved.

\section{CONCLUSION}

One of the key factors of the inequality of teaching quality in Indonesia is the difference in teacher competence in every region of Indonesia. Optimizing the professional com- 
munity of elementary school teachers is a solution to the inequality of teaching quality in Indonesia.

The professional community is an association of teachers to interact and communicate with each other focusing on improving learning and teaching. An effective professional community will show the high intensity of communication among teachers, which of course the communication is focused specifically on teaching and learning. Teachers in the professional community will communicate more often about the progress of their students, develop a curriculum as well as an assessment instrument together and also help other teachers to observe their learning in order to gain a representative reflection of their learning.

Equity of teaching competence can be done with the optimization of teacher professional community activities. Optimizing the professional community of teachers in urban areas can be done by creating an online professional community through the Internet. One of the easy-to-use and relevant Web site applications with the digital capabilities of teachers in Indonesia is Blog. Optimizing the professional community of teachers in remote areas can use auxiliary media such as videos or books that contain the results of professional community activities in urban areas. The role of government is very important in supporting this activity. This should be done on an ongoing basis, so that the gaps in teacher teaching competencies in remote and urban areas can be resolved.

\section{REFERENCES}

Al-Samarrai, S., \& Cerdan-Infantes, P. (2013). Where did all the Money Go? Financing Basic Education in Indonesia. In Education in Indonesia (pp. 109138). Retrieved from http://muse.jhu.edu/books/97898144598 77

Andrews, D., \& Lewis, M. (2002). The experience of a professional community: teachers developing a new image of themselves and their workplace. Educational Research, 44(3), 237-254. https://doi.org/10.1080/00131880210135 340
Bobby, B., Starnes, A., Saderholm, J., \& Webb, A. (2010). A Community of Teachers. Phi Delta Kappan, 92(2), 14. https://doi.org/Article

Boyle-Balse, M. (2005). Preparing community-oriented teachers reflections from a multicultural service-learning project. Journal of Teacher Education, 56(5), 446-458. https://doi.org/10.1177/00224871052821 13

Byrd, K. (2011). What Is a Blog? - Blog Basics. Retrieved from http://blogbasics.com/what-is-a-blog/

Cesareni, D., Martini, F., \& Mancini, I. (2011). Building a community among teachers, researchers and university students. A blended approach to training. International Journal of ComputerSupported Collaborative Learning, 6(4), 625-646.

https://doi.org/10.1007/s11412-0119126-8

Cheng, Y. C., \& Tsui, K. T. (1999). Multimodels of Teacher Effectiveness: Implications for Research. The Journal of Educational Research, 92(3), 141150. https://doi.org/10.1080/00220679909597 589

Chou, C.-H. (2011). Teachers' professional development: Investigating teachers' learning to do action research in a professional learning community. AsiaPacific Education Researcher, 20, 421437. Retrieved from

http://www.scopus.com/inward/record.ur 1 eid=2-s2.0-

$84855228529 \&$ partnerID $=40 \& \mathrm{md} 5=4 \mathrm{c} 7$ 7f952d04c4f6239db2a1f6fe4b5e4

Day, C., Sammons, P., Stobart, G., Kington, A., \& Gu, Q. (2007). Teachers matter:connecting work, lives and effectiveness. Professional learning. https://doi.org/10.1787/9789264022157ja

Demirkasimoğlu, N. (2010). Defining "teacher professionalism" from different perspectives. In Procedia - Social and Behavioral Sciences (Vol. 9, pp. 2047- 
2051).

https://doi.org/10.1016/j.sbspro.2010.12. 444

Duncan-Howell, J. (2010). Teachers making connections: Online communities as a source of professional learning. British Journal of Educational Technology, 41(2), 324-340. https://doi.org/10.1111/j.14678535.2009.00953.x

Farisi, M. I. (2011). Kompetensi Guru dalam Mewujudkan Pendidikan Berkarakter dan berbasis Budaya. Jurnal Teknologi Pendidikan, 11(1)(ISSN 0854-7149), 23-33. Retrieved from http://jm.tp.ac.id/view/1331224689/moh ammad-imam-farisi/kompetensi-gurudalam-mewujudkan-pendidikanberkarakter-dan-berbudaya

Handy, C. B. (1976). Understanding Organisations (4th Editio). London: Pinguin.

Hou, H.-T., Chang, K.-E., \& Sung, Y.-T. (2009). Using blogs as a professional development tool for teachers: analysis of interaction behavioral patterns. Interactive Learning Environments, 17(4), 325-340. https://doi.org/10.1080/10494820903195 215

Hur, J. W., \& Brush, T. A. (2009). Teacher Participation in Online Communities: Why Do Teachers Want to Participate in Self-generated Online Communities of K-12 Teachers? Journal of Research on Technology in Educati, 41(3), 279-303. https://doi.org/10.1080/15391523.2009.1 0782532

Levine, T. H. (2011). Experienced teachers and school reform: Exploring how two different professional communities facilitated and complicated change. Improving Schools, 14(1), 30-47. https://doi.org/10.1177/13654802113982 33

Lieberman, A., \& Miller, L. (2008). Teachers in professional communities. The Series on School Reform.

McLaughlin, M. W., \& Talbert, J. E. (2006). Building school-based teacher learning communities. professional strategies to improve student achievement.

Nurhayati, R. (2017). Indikator Sekolah Efektif. Jurnal Pembangunan Pendidikan: Fondasi Dan Aplikasi, 5(2), 199-208.

https://doi.org/https://doi.org/10.21831/j ppfa.v5i2.18702

OECD. (2016). Education at a Glance 2016: OECD Indicators. OECD Publishing. https://doi.org/10.1787/eag-2016-en

Scott, E. S. (2005). Peer-to-peer mentoring: teaching collegiality. Nurse Educator, 30(2), 52-6. Retrieved from http://www.ncbi.nlm.nih.gov/pubmed/15 785339

Stoll, L., Bolam, R., McMahon, A., Wallace, M., \& Thomas, S. (2006). Professional Learning Communities: A Review of the Literature. Journal of Educational Change, 7(4), 221-258. https://doi.org/10.1007/s10833-0060001-8

Talbert, J. E., \& Mclaughlin, M. W. (2002). Professional Communities and the Artisan Model of Teaching. Teachers and Teaching, 8(3), 325-343. https://doi.org/10.1080/13540600210000 0477

Tang, E., \& Lam, C. (2014). Building an effective online learning community (OLC) in blog-based teaching portfolios. Internet and Higher Education, 20, 7985.

https://doi.org/10.1016/j.iheduc.2012.12. 002

UE, Outlook, E. P., \& UE. (2014). Education Policy Outlook 2015. Ocde. https://doi.org/10.1787/9789264225442en

Van Es, E. A. (2012). Examining the development of a teacher learning community: The case of a video club. Teaching and Teacher Education, 28(2), 182-192. https://doi.org/10.1016/j.tate.2011.09.00 5

Wang, Y. (2011). Blog for teacher implicit knowledge sharing model construction. In Proceedings - 2011 International 
Conference of Information Technology, Computer Engineering and Management Sciences, ICM 2011 (Vol. 3, pp. 363367).

https://doi.org/10.1109/ICM.2011.246

Warren Little, J. (2003). Inside Teacher Community: Representations of Classroom Practice. Teachers College Record, 105(6), 913-945. https://doi.org/10.1111/14679620.00273

Wood, D. R. (2007). Professional Learning
Communities: Teachers, Knowledge, and Knowing. Theory Into Practice, 46(4), 281-290. https://doi.org/10.1080/00405840701593 865

Yang, S. H. (2009). Using blogs to enhance critical reflection and community of practice. Educational Technology and Society, 12(2), 11-21. https://doi.org/10.2307/jeductechsoci.12. 2.11 